\title{
ROOF AND SIDE WALL SHINGLES FROM COCONUT PALM WOOD
}

By

\author{
V.K. Sulc*
}

In a number of coconut palm growing countries, thatched roofs made from indigenous materials such as palm leaves and from suitable tropical grasses such as Imperata cylindirca L. (Cogon) are traditionally used. The most suitable and durable among the palms appear to be the mature leaves of nipa palm. Depending on the quality of leaves and thickness of layers, the serviceable life span of thatched roof is approximalely 5 to 8 years, coconut palm leaves are one of the poorest materials for roofing of permanent dwelling. They easily become brittle when dry and break into bits during rain and wind.

The above materials provide temporary cover, either as roof or as wall walling. Such built shelters ate naturally ventilated and abound in the rural areas.

The influence of western architectural design, urban housing designs use corrugated G.I. metal and other roofing materials. Where is not necessarily suitable to climatic conditions and depending on economic situation, G.I. sheets used are usually of very light gauge.

The idea to use shingles from coconut palm wood as substitute for roofing material easily can gain advantages in most coastally populated areas. The effect of seawater moisture can be much more considerable as application of protective coats or paints can be avoided. Coconut Palm wood roof shingles arc generally attractive in appearance and provide adequate insulation against heat. However, coconut palm wood roof shingles could not necessarily be considered as cheap material for low cost housing projects. It takes experienced labour to set such type of roof and choice of appropriate nails especially when the shingles were previously treated.

\section{A. Manufacturing Roof and Side Wall Shingles}

Considerable technological difficulties and production of substandard products can be expected if conventional method of making shingles is employed for coconut palm wood. The formation of Coconut Palm wood with large density gradient and consequently large variation in wood properties is the basic reason why such manufacturing method is not suitable for coconut palm wood and cannot be recommended.

Brief comments on the conventional method of making shingles from suitable wood species :

1. Round wood is accurately cross cut to "blocks" of a convenient length, e.g., depending on the required length of shingles.

2. Blocks are quartered either by saw or mechanical splitter and reduce still further, if necessary, to suitable sizes for the shingle machine.

3. Splitted blocks then pass through a special saw where bark, sapwood, or defects are removed.

*Wood Technologist, Present address: 2 Teague Road Cook, Act 2614 Canberra, Australia. 
4. Shingles are cut from blocks vertically positioned by special shingle saw using a small tilting reciprocal carriage so that tapered shingle is produced by each saw cut along the radial surface cxposed by splitting.

5. In the process, butt of shingles is cut from top of log on one stroke, then from the bottom on second stroke.

6. Then shingles pass through a shingle Jointer for edging (to produce parallel edges or, if necessary, to remove defects).

7. Finished shingles are then graded and dried usually in binded bundles ( 4 bundles should cover one square of roof, $10 \times 10 \mathrm{ft}$ or $9 \mathrm{~m}^{2}$ ). Shingles made from less durable species are usually treated by wood preservative.

8. Standard dimension of shingles (measured in green condition):

length $: 400 \mathrm{~mm}, 450 \mathrm{~mm}$, or $600 \mathrm{~mm}$

width : random width 75 to $300 \mathrm{~mm}$, or dimensional shingles supplied in definite width

thickness : thickness of shingles measured on the butt - a number of butts make up a special dimension such as $4 / 2,5 / 2$, or $5 / 21 / 4$, e.g., $4 / 2$ means that 4 butts are required to equal 2 inches, etc.

Note: Splitted shingles are called shakes. The term "shakes" apply probably to the oldest type of handmade shingles. Hand made splitted "shakes" are made, by splitting, from the longer round wood blocks usually $625 \mathrm{~mm}$ to $900 \mathrm{~mm}$ long. $12 \mathrm{~mm}$ up to $30 \mathrm{~mm}$ thick and width is random from $125 \mathrm{~mm}$ to $450 \mathrm{~mm}$.

\section{Method of Shingle Manufacturing from Coconut Palm Wood}

The process and necessary machinery are very simple based on ripsawing the prepared shingle blanks of required dimension, and positioned on the edge from corner to corner, thus producing two shingles by one out.

Coconut palm wood shingle blanks are made from climensionally sawn boards and ail three density groups of wood - hard, medium, soft can be used to produce different grades of shingles for the definite end-use application.

Shingles can be produced of random (limited) width but it has been found that dimensional shingies (uniform width) provide better utilization and application.

\section{Process:}

1. Dimensionally sized green board of cross section $100 \mathrm{~mm} \times 25 \mathrm{~mm} \pm 2 \mathrm{~mm}$ tolerance are accurately crosscut to the desired length of shingle blanks.

Length of blanks is equal to the intended length of the shingles.

Standard length of shingles made from Coconut Palm wood: $400 \mathrm{~mm}$ (16 inches), or $600 \mathrm{~mm}$ (24 inches)

Note: Shingle products made possible the utilization of partly defective or short length boards. Blanks for making shingle must be defect-free, therefore, ail defects in the length of a board are progressively clocked out. 


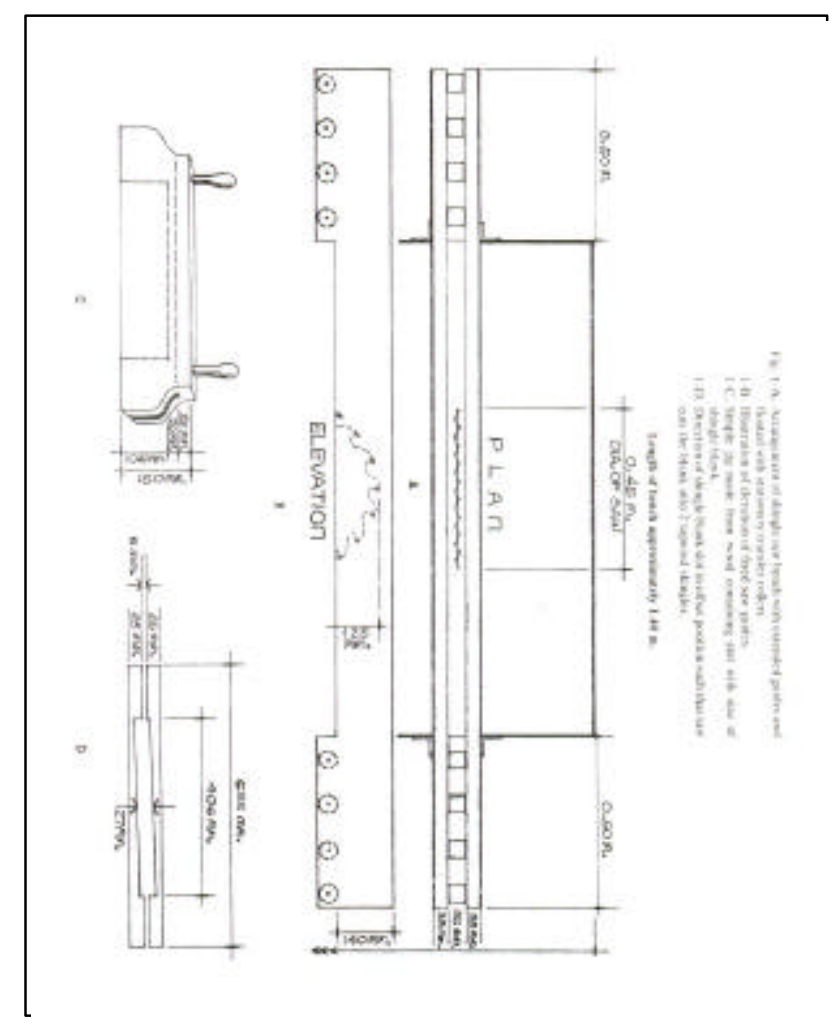

2. Shingle blanks are stacked close to shingle saw and processed as soon as possible. (Sawing or machining Coconut Palm wood in green condition is considerably less difficult).

Fig. 1 illustrates a simple bench rip saw fitted with $450 \mathrm{~mm}$ strobsaw $^{1)}$ (Fig. 2 ) powered by $10 \mathrm{HP}$ ( $\mathrm{kw}$ 7.5) electric motor. The bench table is fixed with two permanent guides, one on each side of the saw to provide channel where the jig holding the shingle blank passes through the circular saw.

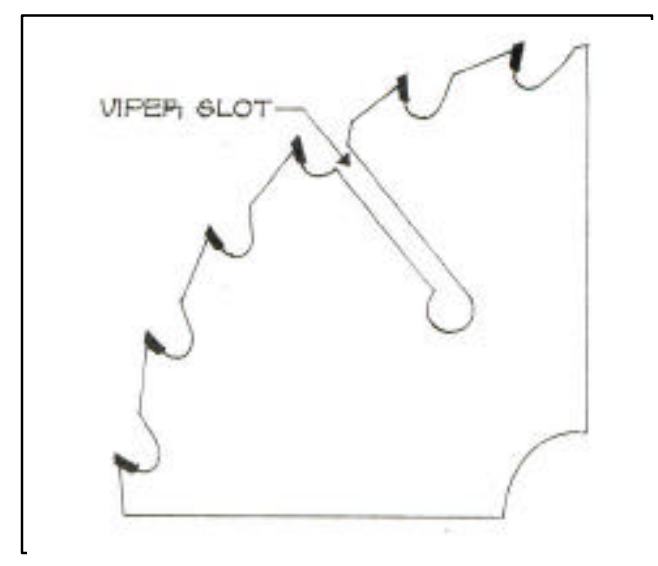

Fig. 2. Carbide-tipped strobsaw fitted with two viper slots

1) Strobsaw is manufactured bN, "Sanvik" and is obtainable in limited different diameters. At PCA-Zamboanga Research Center, a strobsaw is used for cutting shingles. Specifications: $400 \mathrm{~mm}$ diameter, G $11(3.05 \mathrm{~mm}), 22$ tungsten carbide-tipped teeth producing $5 \mathrm{~mm}$ kerf, hook (rake angle) is $20^{\circ}$, blade is fitted with viper slot on each side of piate and which secure clear kerf free of slivers and irreizularities and reducc the risk ot binding. Peripheral speed of saw is $40 \mathrm{~m} / \mathrm{sec}$ which is approximately $2,500 \mathrm{~m} / \mathrm{min}$. RPM 1780 . 


\section{B. General Comments on Quality and Service of Coconut Palm Wood Shingles.}

1. Durability of Coconut Palm wood shingles should be increased by preservation treatment, where possible pressure treatment is preferred. Dipping or brushing the whole shingles by suitable wood preservative, before they are laid is less effective. Repeated brush application in 2 or 3 years time on the exposed surface is recommended.

\section{2. $\quad$ Splitting}

a) by driven nails. When shingles are laid, they should be predrilled by drill bit 2 gauges smaller than the diameter of nails.

b) by exposure to weather and effect of shrinkage or warping. Shingles should be laid on the roof or sidewalls as close as possible to equilibrium moisture content (16\%) with expansion joint between shingles 5 to $6 \mathrm{~mm}$ wide. Green shingles, when nailed in the position and dry afterwards, could develop drying stress between nails, especially shingles made from high density wood can split.

3. Dimensional stability

Coconut palm wood has low to moderate shrinkage, in general, and has very low ratio (close to unity) of tangential to radial shrinkage. Therefore, if laid in dry condition, the shingles can be considered dimensionally stable.

4. Weight of shingles

The weight of shingles depends on the wood density group from which shingles are made.

a) Roofing shingles should have approximate average basic density of $600 \mathrm{k} \mathrm{g} / \mathrm{M} 3$ (density range between 500 to $700 \mathrm{~kg} / \mathrm{m} \mathrm{3}$ ).

One thousand shingle blanks, $25 \mathrm{~mm}$ x $400 \mathrm{~mm}$, equal one cubic meter. When shingle blanks pass through shingle saw, 2,000 pieces of shingles are produced with the following dimension:

$\begin{array}{ll}\text { length } & : 400 \mathrm{~mm} \\ \text { thickness (at butt) } & : 12.5 \mathrm{~mm} \\ \text { width } & : 100 \mathrm{~mm}\end{array}$

i) When laid on the roof with $160 \mathrm{~mm}$ weather exposure, it takes 60 shingles to cover $1 \mathrm{~m}^{2}$.

Weights of 60 shingles $\left(1 \mathrm{~m}^{2}\right.$ laid on the roof) in different moisture contents and recommended basic density range are as follows :

At $16 \% \mathrm{MC}^{1)}$ - weigh approximately $16 \mathrm{~kg}$.

At $25 \% \mathrm{MC}$ - weigh approximately $17.5 \mathrm{~kg}$.

Fully saturated (green) or affected by prolonged rain can reach up to $25 \mathrm{~kg}$., if not treated by waterproof preservative.

ii). When laid on the roof with $125 \mathrm{~mm}$ weather exposure (recommended weather exposure), it takes 80 shingles to cover $1 \mathrm{~m}^{2}$. 
Weights of 80 shingles ( $1 \mathrm{~m}^{2}$ laid on the roof) in different moisture contents and recommended basic density range are as follows:

At $16 \% \mathrm{MC}$ - weight $21.6 \mathrm{~kg}$

At $25 \% \mathrm{MC}$ - weight $23.0 \mathrm{~kg}$.

Fully saturated (green) or affected by prolonged rain can reach up to $34 \mathrm{~kg}$., if not treated by water roof preservative.

b) Sidewall shingles

i) external application

Shingles should have average basic density of $500 \mathrm{~kg} / \mathrm{m}^{3}$ (density range is $400 \mathrm{~kg} / \mathrm{m}^{3}$ and above).

$\begin{array}{ll}\text { Standard dimension } & : \\ \text { length } & : 400 \mathrm{~mm} \text { or } 600 \mathrm{~mm} \\ \text { thickness (at butt) } & : 12.5 \mathrm{~mm} \\ \text { width } & : 100 \mathrm{~mm}\end{array}$

Sixty pleces of shingles, $400 \mathrm{~mm}$ long, exposed $163 \mathrm{~mm}$ to weather, are needed to cover $1 \mathrm{~m}^{2}$ of wall siding.

If $600 \mathrm{~mm}$-long shingles with $275 \mathrm{~mm}$ exposure to weather are used. 37 pieces are needed to cover $1 \mathrm{~m}$ of wall siding.

ii) internal wall shingles

Internal wall shingles are made from wood with average basic density $300 \mathrm{~kg} / \mathrm{m}^{3}$ and above.

$\begin{array}{ll}\text { Standard dimension } & : \\ \text { length } & : 400 \mathrm{~mm} \text { or } 600 \mathrm{~mm} \\ \text { thickness (at butt) } & : 12.5 \mathrm{~mm} \\ \text { width } & : 100 \mathrm{~mm}\end{array}$

$400 \mathrm{~mm}$-long shingles

The shingles can be laid in single or double course.

Single course installation is the same as for the roof covering, only weather exposure could be slightly larger. See Fig. 3

Double course consists of 80 shingles for the undercourse (lower grade) and another 80 shingles for the second "face course" with weather exposure of approximately $160 \mathrm{~mm}$, most of the shingle surfaces are exposed. See Fig. 15 . To cover $1 \mathrm{~m}^{2}$ of wall siding, approximately 60 pieces of shingles are used.

\footnotetext{
${ }^{1)}$ Moisture content
} 


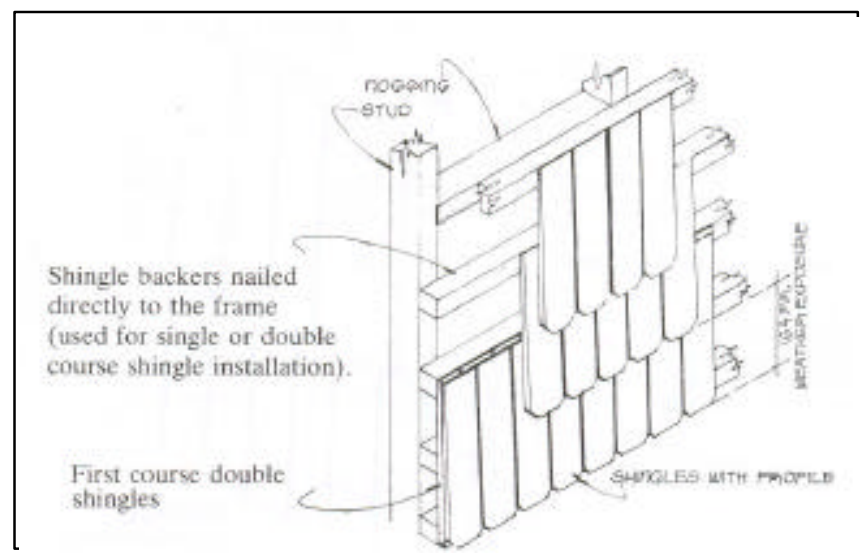

Fig. 3 Single course shingles for the sidewalls.

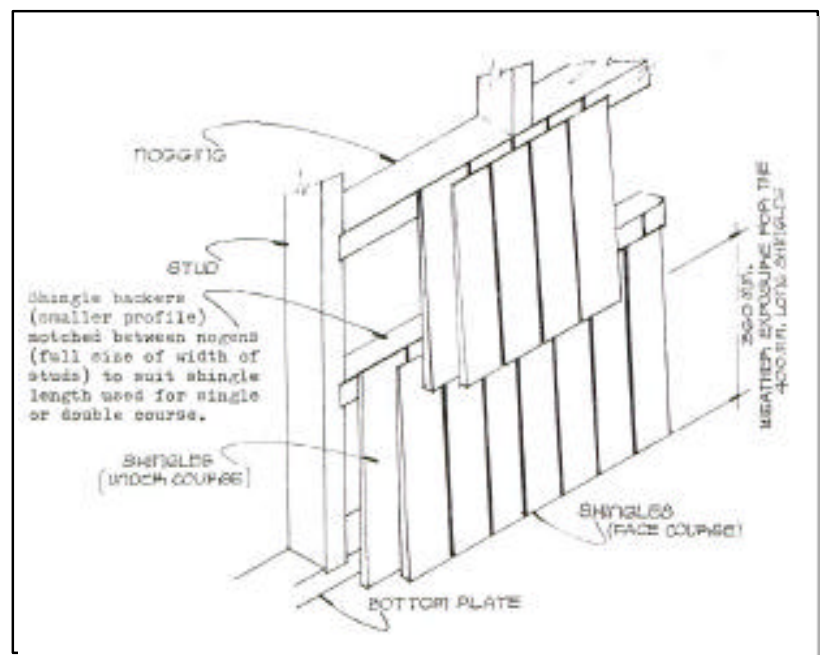

Fig. 4. Double course shingles for the interior sidewalls

5. Strength and weathering

Coconut palm wood shingles made from oto density wood has sufficient strength for roofing or exterior all siding.

Weathering by the combined effect of sunlight and rain tends to raise the grains (vascular elements). At the same time, erosion of ground parenchyma tissues takes place for the lower density Coconut Palm wood.

The decomposition of softer tissues by ot ultra-violet rays can be controlled by the wood preservative containing copper and chromium to minimize the absorption of RFMI rw rays.

Internal wall shingles made from low wood and fully protected from weather extremities give end-use service.

6. Coconut palm wood has ability to take wood preservatives by pressure, dipping, brushing, etc. 
7. Appearance

Coconut palm wood shingles produce exceptionally good appearance when used as roofing or wall siding.

8. Economics

The process of making roof or sidewall shim- from coconut palm wood does not require expensive machin and the possibility to utilize short pieces of wood applies o all coconut palm growing countries, especially in some Pacific islands where palm stems are relatively short and twisted. Such utilization of the short pieces of wood makes possible to product a product and its end use of considerable commercial and aesthetic vaiue.

Shingle covered roof has exceptionally g insulation properties and good appearance from outside and inside. Therefore, ceiling is not necessarily required. When metal material is used, some insulation is necessary against heat Mitol.

The argument if locally made coconut iss wood shingles in replacing imported roofing and wall sibuilding materials (sometimes of a low quality) is acceptable for the lowcost housing, is a subject of a number of consideration such as local employment, new skill, savings or relocating import quota, more comfortable housing, etc.

Note: A shingle saw as illustrated in Fig. 1 can produce from available shingle blanks, with relative unskilled operators, between 3,500 to 4,000 shingles per working day. This is based on the study that operators work 6 hours in hours shift with such effort which can be repeated day after day.

\section{Recovery from Coconut Palm Round Wood Converted to Shingles}

A study was carried out at the Zarnboanga Research Center of the Philippine Coconut Authority to convert palm stems to shingles. The combined total volume of the palm stems is $3.7 \mathrm{~m}^{3}$ and the average height is 17.8 meters (from butt to first leaf). The palm stems were converted to boards with cross section dimension of $100 \times 25 \mathrm{~mm}$ which were cross cut to shingle blanks, $25 \times 100$ $\mathrm{x} 400 \mathrm{~mm}$, then sawn to shingles.

The following recovery was obtained by visual grading after air drying to $16 \%$ moisture content (equilibrium moisture content).

Average $\mathrm{BD}^{1)} 450 \mathrm{~kg} / \mathrm{m}^{3}$ and above .... 994 pieces

Average BD below $450 \mathrm{~kg} / \mathrm{m}$........... 806 pieces

"Reject shingles" usable as under course for the double course shingles application or secondary type of buildings

202 pieces

Total 2,002 pieces

Note: Rejects mostly came from shingles made from very low density wood.

Shingles recovery from $3.7 \mathrm{~m} 3$ volume of round wood: $1 \mathrm{~m}^{3}$ shingle blanks $(1,000)$ is equivalent to 2,000 shingles.

Therefore, percentage of recovery obtained is approximately 27 percent.

Note: $3.7 \mathrm{~m}^{3}$ volume of round wood was based on the total volume of stems, e.g., from butt to first leaf. This explains the larger proportion of the recovery of low density shingles. Selected palm stems were slightly below average in reference to the general quality of local mature coconut palm. 


\section{Grading Shingles}

Shingle blanks must be free of defects when cross cut from boards to required length. For this reason, when the blanks are processed to shingles, very few are defective as all defects are docked out during the cross cutting of shingle blanks.

Coconut palm wood shingles can be made from blanks of a mixed density, then air dried before visual grading by density groups and defects or imperfections.

Shingles should always be visually graded after drying to equilibrium moisture content (approximately 16\%) to include defects developed during the drying process.

Fig. 5 shows methods of drying shingles in a drying shed with open sides. Air drying green shingles during dry weather could be completed in about 4 weeks time to equilibrium moisture content.

An experienced grader with bmk6 knowledge of coconut palm wood can visually grade air dried shingles to appropriate density groups and for possible defects, then sort them, at the same time, for the final end-use- without much. This is done by utilizing the knowledge of the visual appearance of surface such as color of wood, size of texture of grain (vascular elements) and judgment of the weight.

1. Roofing shingles should be. made from wood with average basic density range 500 to maximietee $700 \mathrm{~kg} / \mathrm{m} 3$.

Shingles made from very high density wood should be excluded from roof installation as ther have tendency to split when exposed to weather conditions.

Recommended dimension of roofing shingles:

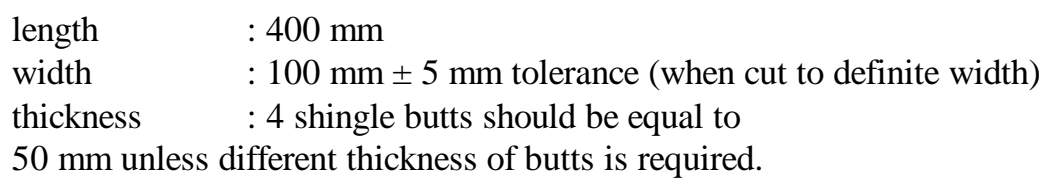

General rules :

a) No bark should be included.

b) Edges should be parallel.

c) Ten percent of shingles can be $25 \mathrm{~mm}$ longer or shorter.

d) No warping in allowed. Shingles should lay flat.

e) Wane on one side should not exceed 1/10 of width or thicknees or both.

f) Splits or severe checks are not allowed on the butt side. (Small splits are allowed on the tapered side not exceeding $1 / 4$ of length.)

g) Reject roofing shingles can be used for second buildings, wall siding, or undercourse layer for double course shingle application.

2. Wall siding shingles

a) exterior wall siding shingles - average basic density range $400 \mathrm{~kg} / \mathrm{m}^{3}$ and above. (No limit for shingles made from high density wood.) 
Fig. 5 Arrangement for drying roof or sidewall shingles.
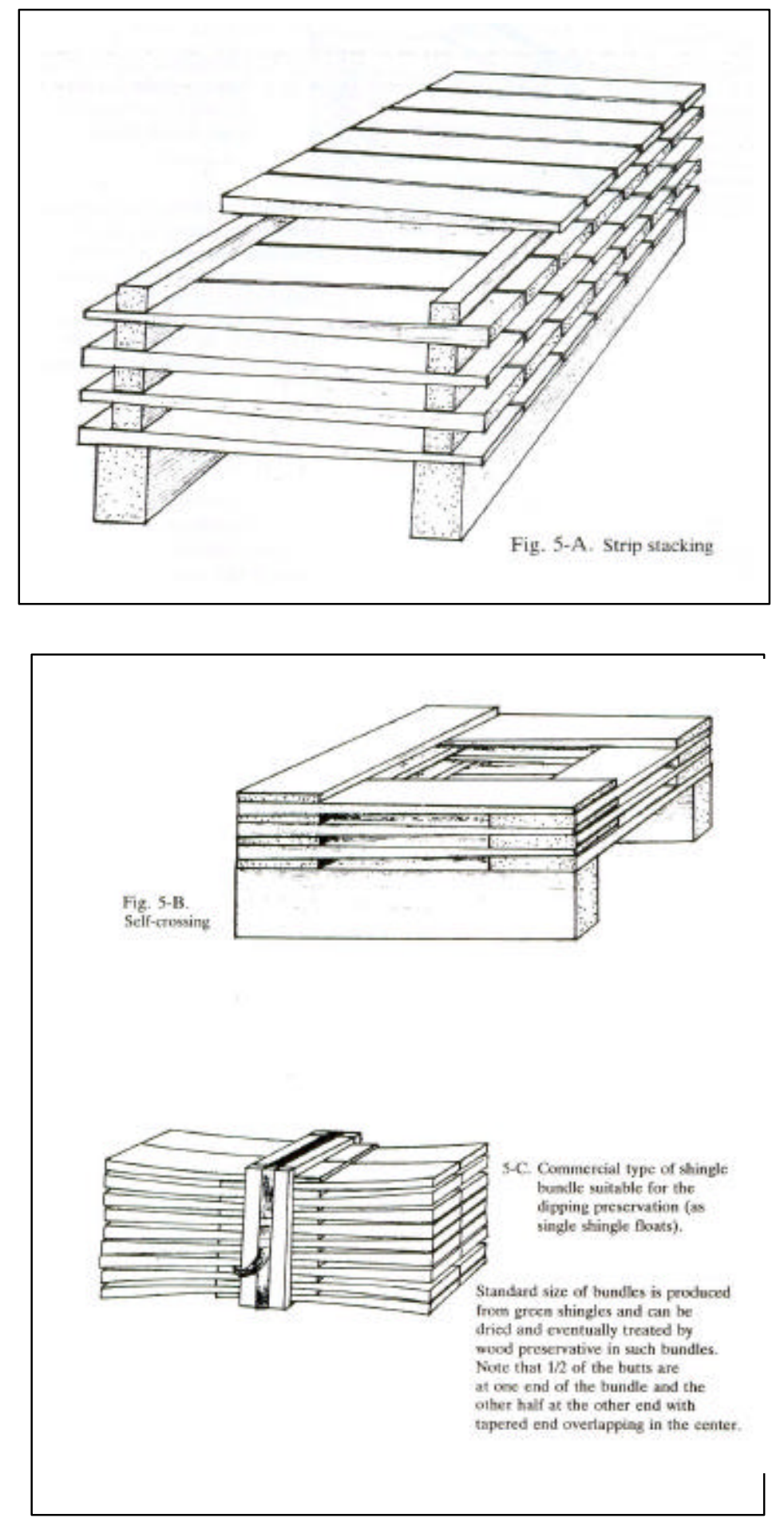

Dimension:

length

: $400 \mathrm{~mm}$ or $600 \mathrm{~mm}$

width

$: 100 \mathrm{~mm} \pm 5 \mathrm{~mm}$ tolerance

thickness

: 4 shingle butt ends should be equal to $50 \mathrm{~mm}$ unless different thickness of butts is required. 
Note: Sidewall shingles can be made from coconut palm wood of random width from $75 \mathrm{~mm}$ to $125 \mathrm{~m}$ if desired.

Because exterior sidewall shingles are partly protected, they have usually excess life to roof shingles.

In general, rules which apply to roof shingles apply to exterior wall siding shingles.

Exterior wall siding shingles are sometimes surfaced and can be machined to desired profile (see Fig. 6), then treated by suitable wood preservative. After installation, colored wood stain can be applied by brushing.

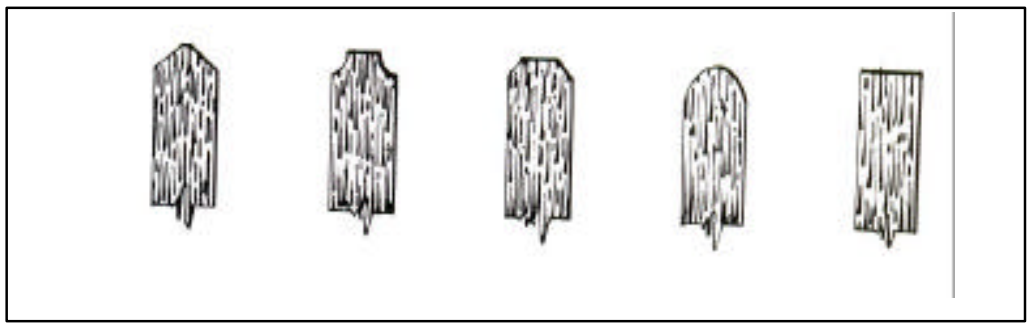

Fig. 6 Different profiles of sidewall shingles

Any butt shingle profile can be used for sidewalls application. Exception: roof shingles should always have plain (square) profile of butt end.

Weather exposure for the exterior wall siding shingles can be slightly increased.

b) internal wall siding shingles - average basic density range $250 \mathrm{~kg} / \mathrm{m}^{3}$ and above. (No limit for shingles made from high density wood.)

Dimension:

$$
\begin{array}{ll}
\text { length } & : 400 \mathrm{~mm} \text { or } 600 \mathrm{~mm} \\
\text { width } & : 100 \mathrm{~mm} \pm 5 \mathrm{~mm} \text { tolerance } \\
\text { thickness } & : 4 \text { shingle butts should be equal to } 50 \mathrm{~mm} \text { unless different thickness of butts } \\
& \text { is required. }
\end{array}
$$

It is recommended that internal shingles should be treated by Boron type of chemicals as a protection against Anobium species wood borers.

Shingles used for internal wall sidings are usually surfaced and sanded. They can be machined to desired profile butts as shown in Fig. 5 and then finished by natural clear finish or by suitable colored wood stain.

Shingles can be laid in single course (see Fig. 3), or in double course (see Fig. 4).

Note: For double course shingles, the underlayer (first course) can be made from rejects or lower quality shingles of different densities.

For the internal wall sidings, shingles made from large density range can be used. Mixing different densities during installation depends on the choice, or using sorted density for each different wall probably produces a better visual effect. 


\section{E. General Comments on Installation of Shingles}

Installation of shingles is a subject of practical skill and experience, but it is not difficult to obtain the necessary skill when recommended rules are observed:

1. First course must be double laid for the single course sidewall and roof shingles. See Figs. 3 and 7 (Exception: internal double course wall sidings).

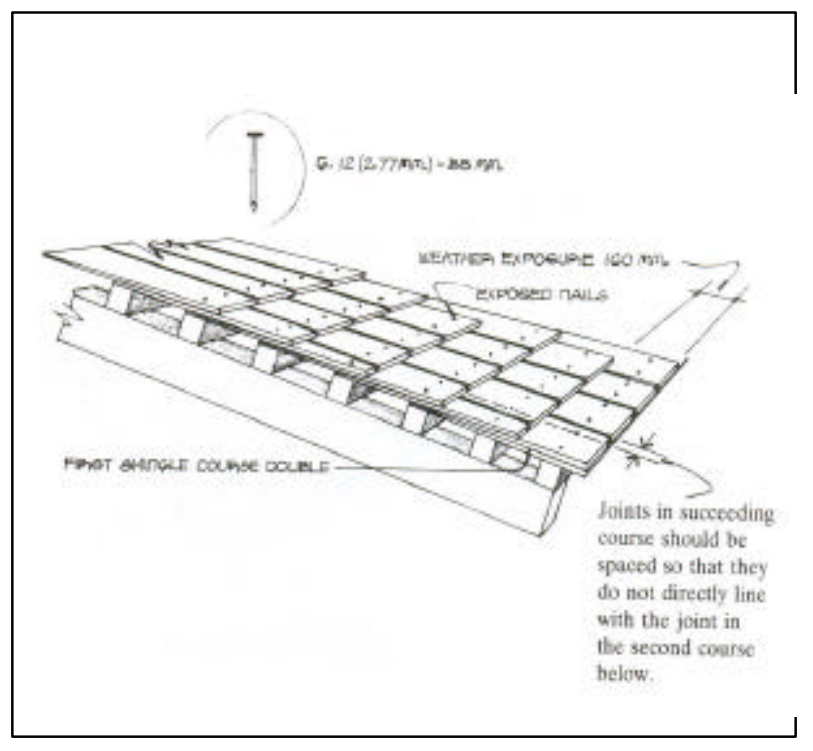

Fig. 7. Roof shingles with $164 \mathrm{~mm}$ weather exposure, therefore, 4 nails are used for each shingle (2 nails exposed).

2. Nails

G 12 (2.77 mm diameter), $38 \mathrm{~mm}$ long, rustproof nails such as galvanized stainless steel, or cadmium coated if obtainable, preferably with ring shank (threaded tail).

Internally laid shingles laid with common finishing nails are usually punched and sealed by wood putty.

If weather exposure is larger as $164 \mathrm{~mm}, 4$ nails are necessary to hold the shingles flat with 2 nails exposed to weather. See Fig. 7.

When roofing shingles are weather exposed $125 \mathrm{~mm}$, only two nails per shingle should be used and nails should always be covered by the succeeding course. See Flig. 8 .

Installation of the roof shingles with $125 \mathrm{~mm}$ weather exposure and using only 2 nails per shingle is preferred taking into account that up to 25 percent more shingles are necessary to cover the given areas.

Coconut palm wood shingles must be pre-drilled to avoid splitting. The nails should be driven at minimum $44 \mathrm{~mm}$ from the butt and $25 \mathrm{~mm}$ from the side edge. 


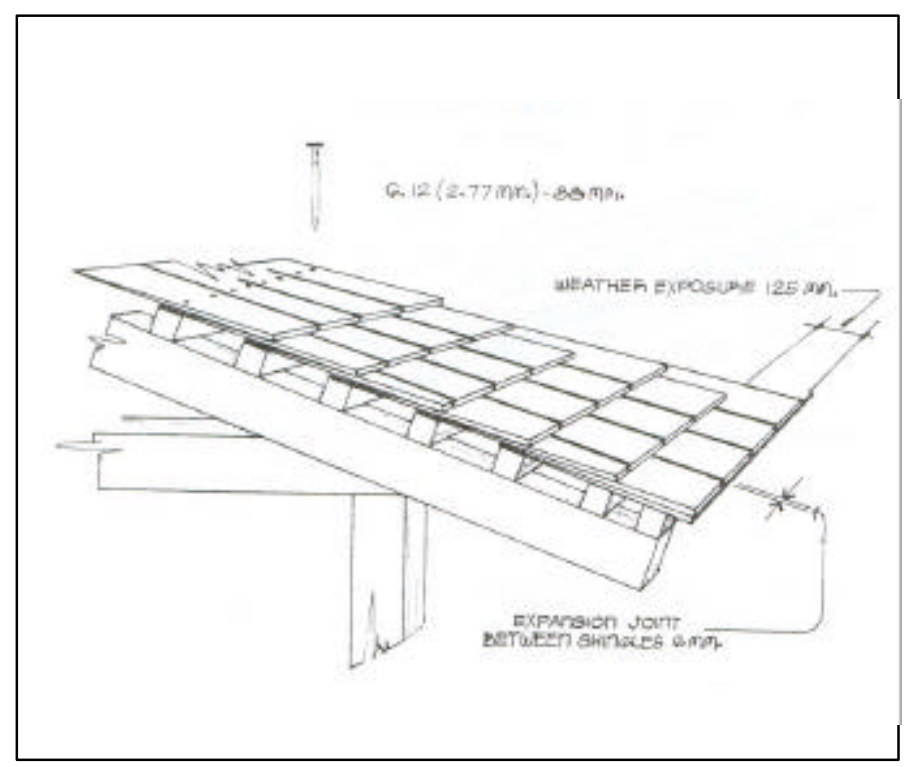

Fig. 8. Roof shingles with $125 \mathrm{~mm}$ weather exposure. Only 2 nails are used for each shingle, e,g., no nails are exposed.

3. Expansion joint between shingles (space between shingles) should be 5 to $6 \mathrm{~mm}$. See Fig. 8 . The joints between shingles should be offset minimum $38 \mathrm{~mm}$ from the joints between shingles in the course below. See Fig. 9. The joints in the succeeding course should be spaced so that they do not directly fine with the joints in the second course below. See Fig. 7

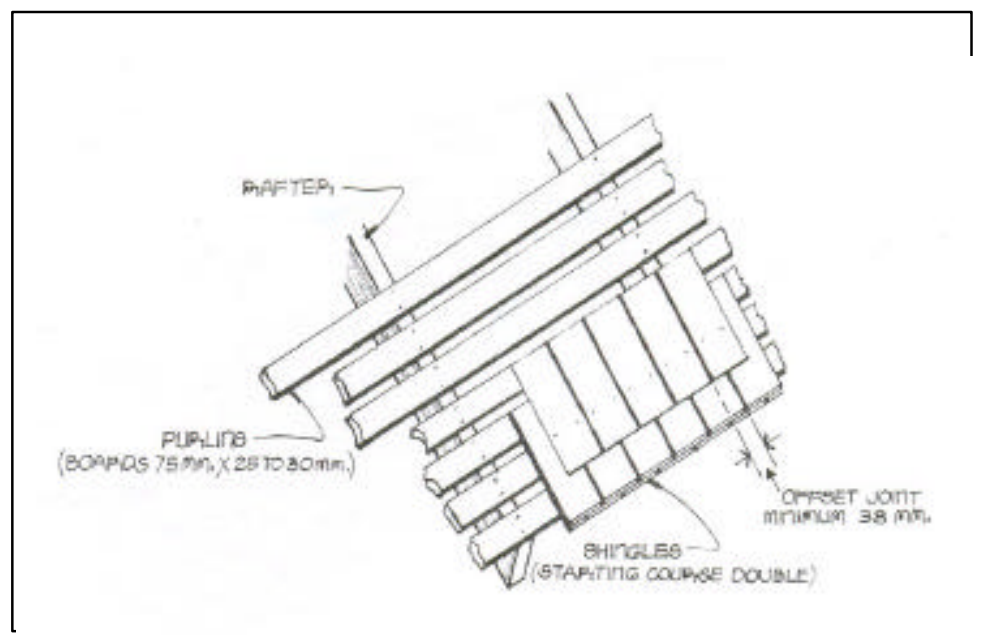

Fig. 9. Spaced-type (purlins) board roof. Note the offset (overlap) joints between succeeding shingle courses.

\section{Shingle backers}

Will siding shingles can be nailed directly to the framing members, or to battens connected to frame. See Figs. 3 and 4

Roof shingles can be nailed to boards, approximately 75 x $32 \mathrm{~mm}$. See Fig. 20. Such arrangement provide acceptable internal ceiling finish and provides ventilation for internal surface of shingles. 
Roof shingles can also be nailed to standard type of purlins with cross section depending on spacing of trusses or rafters. See Fig. 10.

Note: In humid climatic conditions, shingle underlying materials such as plywood or closed wood decking should not be used as it is necessary to provide good ventilation to keep the internal surfaces of shingles dry.

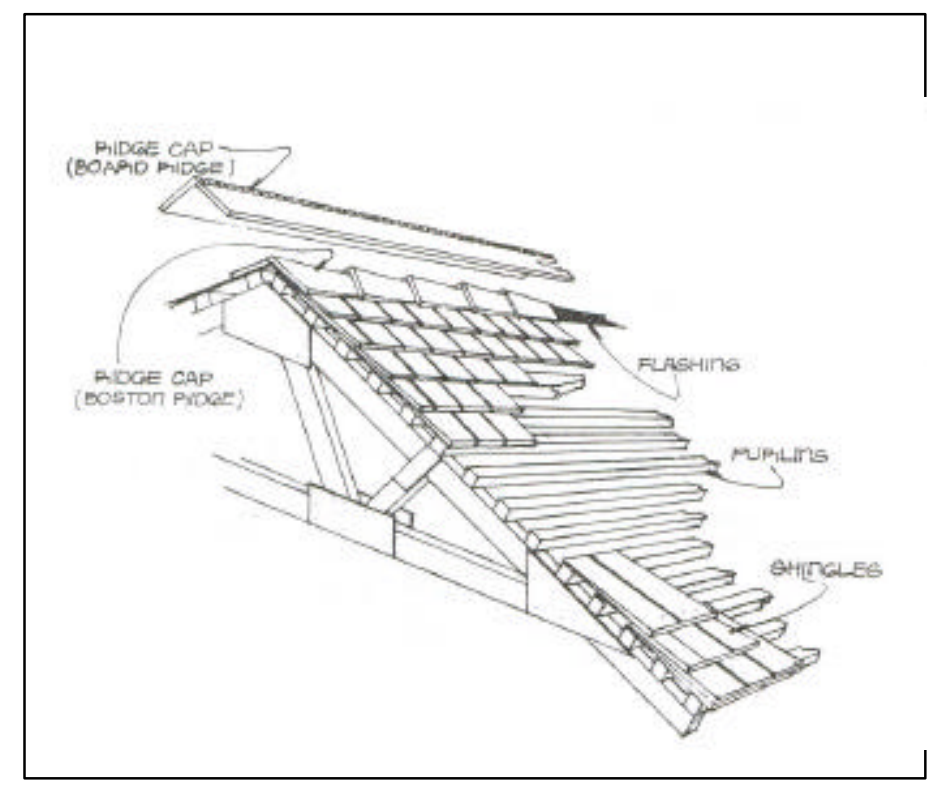

Fig. 10. Standard type of purlins cross section $38 \times 44 \mathrm{~mm}$ used for $1.75 \mathrm{~m}$ spaced trusses. Permitted maximum overhang on gable side is $600 \mathrm{~mm}$ without framing overhang (flying rafter).

5. Shingles should be overhanged on the eave side about $32 \mathrm{~mm}$ and on the gable side minimum $18 \mathrm{~mm}$.

6. Slope of roof

Shingles weather exposure depends on the slope of the roof. If the slope of roof is less than 25 degrees, the weather exposure must be reduced. The recommended slope is minimum 25 up to 35 degrees.

7. Flashing of roof (see Fig. 10)

Flashing of the roof ridge is necessary and flashing of overhang by strip of flashing material at least 3 to 4 shingles wide on the gable side is recommended.

8. Shingles should not be wet or soak in water prior to installation. Splitting due to shrinkage stress betwen nails vvill occur if shingles are laid wet.

F. General Comments on Preservation Treatment of Coconut Palm Wood Shingles.

Coconut Palm wood roofing or external wall siding shingles should be treated by wood preservative before installation. Where it is possible, pressure treatment is preferred. When not available, dipping or brushing can be employed although such methods are less effective. 
Pressure treatment. Waterborne preservatives such as Tanalith $\mathrm{C}$ applied by pressurized tank (Bethell method) has been used for roof shingles at the Zamboanga Research Center of the Philippine Coconut Authority.

Roof shingles air dried to approximately 16 to 18 percent moisture content and pressure treated by 2 percent Tanalith $C$ solution obtained preservative retention of 12 to $14 \mathrm{~kg} / \mathrm{m}^{3}$ ( 4.2 to 4.9 $\mathrm{kg}$ of active elements). There were 2,564 pieces of shingles treated, $400 \mathrm{~mm}$ long, $100 \mathrm{~mm}$ wide and $12.5 \mathrm{~mm}$ thick at butt (thickness of 4 shingle butt equals $50 \mathrm{~mm}$ ).

Hot and cold bath. Hot bath is provided by pure water (no chemicals added). Cold bath can be from 5\% to $10 \%$ concentration of Tanalith C. Air dry (equilibrium moisture content) shingles were dipped in water which is about $70^{\circ} \mathrm{C}$ and brougbt water to boiling point in approximately 60 minutes. Then the shingles were dipped into a cold solution of $6.6 \%$ concentration of Tanalith $\mathrm{C}$ for about 60 minutes. The obtained retention was $7 \mathrm{~kg} / \mathrm{m}^{3}$ (2.45 kg of active elements) of shingles (2,564 pieces).

Penetration

1. Shingles treated by pressure Bethell method by Tanalith $\mathrm{C}$

High density wood - Irregular penetration, minimum $2 \mathrm{~mm}$ from ail faces.

Medium density wood -70 to $90 \%$ penetration, minimum $4 \mathrm{~mm}$ from all faces.

Low density wood - Complete penetration.

2. Shingles treated by hot and cold bath

Air dry: High density wood $\quad-1$ to $1.5 \mathrm{~mm}$ penetration from all faces.

Medium density wood $\quad-1.5$ to $2 \mathrm{~mm}$ penetration from ail faces.

Low density wood

- Irregular penetration through whole thickness and ail sides.

Green: High density wood - Irregular penetration approx. $1 \mathrm{~mm}$ from ail sides.

Medium density wood - Irregular penetration of $1.5 \mathrm{~mm}$ from ail sides.

Low density wood $\quad$ - Irregular penetration, minimum $2 \mathrm{~mm}$ from ail sides.

Note: Shingles made from low density wood arc not usually treated by wood preservative as they are installed only for interior wall sidings. (Treatment by diffusion method by Boron compounds is recommended.)

\section{Double diffusion treatment}

Another method used for preservation of shingles at the Zamboanga Research Center of the Philippine Coconut Authority is the modified double diffusion treatment. See Fig. 11. steel tank ${ }^{1)}$

$5 \%$ solution of copper sulphate (CUS04) was heated to 700 to $800 \mathrm{C}$ (not more) in a stainless

Bundles of shingles were submerged in the solution and the temperature was maintained for 5 hours. Then the shingles were transferred to the cold bath tank containing 5\% solution of sodium dichromate $\left(\mathrm{Na}_{2} \mathrm{Cr}_{2} \mathrm{O}_{7}\right)$ and $5 \%$ arsenic pentoxide $\left(\mathrm{AsO}_{2} 2 \mathrm{H}_{2} \mathrm{O}\right)$ and were kept in solution for 48 hours.

') Ordinary steel tank cannot be used for the solution of $\mathrm{CuSO}_{4}$ in high temperature as it will rapidly attack steel. When temperature is increased above $80^{\circ} \mathrm{C}$, the solution could attack welded joints in the stainless steel tank. 


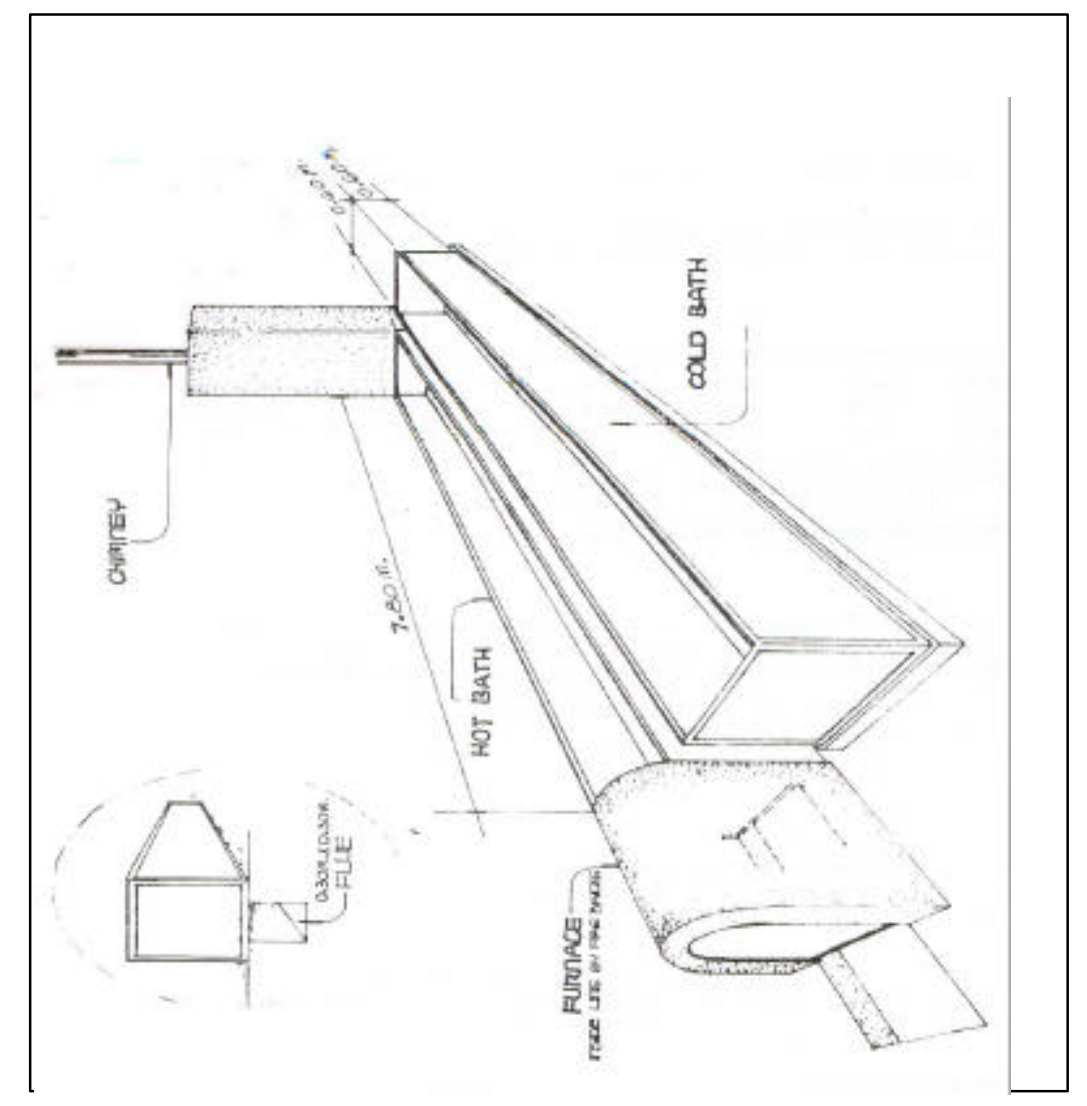

Fig. 11 Sketch of hot and cold open tanks used for Impregnation of transmission poles \& shingles

Brief test of the efficiency of waterproof preservative for the shingles as described above. or brushing.

Absorption of moisture is expressed as a percentage of the weight of shingles before dipping

1. Treatment was applied by dipping the shingles in waterproof preservative for 30 seconds. after brief surface drying, the shingles were submerged in water for 30 minutes.

\begin{tabular}{|l|c|c|c|c|}
\cline { 2 - 5 } \multicolumn{1}{c|}{} & \multicolumn{3}{c|}{ Absorption of moisture in percent } \\
\cline { 2 - 5 } \multicolumn{1}{c|}{} & $\begin{array}{c}\text { Untreated } \\
\text { Shingles }\end{array}$ & Control & $\begin{array}{c}\text { Treated } \\
\text { Shingles }\end{array}$ & control \\
\hline High density & 1.97 & 5.6 & 1.15 & 3.6 \\
Medium density & 4.16 & 12.62 & 1.75 & 5.9 \\
Low density & 7.43 & up to 24 & 2.3 & 18.6 \\
\hline
\end{tabular}

2. Treatment was applied by dipping the shingles in waterproof preservative for 15 minutes. after brief surface drying, the shingles are submerged in water for 30 minutes.

\begin{tabular}{|l|c|c|c|c|}
\cline { 2 - 5 } \multicolumn{1}{c|}{} & \multicolumn{3}{c|}{ Absorption of moisture in percent } \\
\cline { 2 - 5 } \multicolumn{1}{c|}{} & $\begin{array}{c}\text { Untreated } \\
\text { Shingles }\end{array}$ & Control & $\begin{array}{c}\text { Treated } \\
\text { Shingles }\end{array}$ & control \\
\hline High density & 1.15 & 1.5 & 0.8 & 2.53 \\
Medium density & 4.40 & 9.0 & 1.2 & 3.77 \\
Low density & 5.70 & 10.0 & 2.3 & 6.53 \\
\hline
\end{tabular}


3. For hard density shingles only, treatment was applied by brush. After 30 minutes, the shingles were submerged in water. Absorption of moisture was $1.4 \%$.

4. Square blocks, $50 \mathrm{~mm}$ cube, absorption of moisture was $0.7 \%$.

\begin{tabular}{|c|c|c|c|}
\hline \multicolumn{2}{|c|}{$\begin{array}{l}\text { Moisture condition/ } \\
\text { Density of shingles }\end{array}$} & \multirow{2}{*}{$\begin{array}{l}\text { Retention } \\
15.84 \mathrm{~kg} / \mathrm{m}^{3} \\
(5.56 \mathrm{~kg} \text { of active elements) }\end{array}$} & \multirow{2}{*}{$\begin{array}{l}\text { penetration } \\
\text { Irregular, at least } 2 \mathrm{~mm} \\
\text { From all sides }\end{array}$} \\
\hline Air dry: & high density & & \\
\hline & $\begin{array}{r}\text { Basic density 1) } \\
500 \text { to } 700 \mathrm{~kg} / \mathrm{m}^{3}\end{array}$ & $\begin{array}{l}18.70 \mathrm{~kg} / \mathrm{m}^{3} \\
(6.56 \mathrm{~kg} \text { of active elements) }\end{array}$ & Complete \\
\hline Green: & high density & $\begin{array}{l}7.98 \mathrm{~kg} / \mathrm{m}^{3} \\
\text { (2.80 kg of active elements) }\end{array}$ & $\begin{array}{l}\text { Irregular, at least } 1 \mathrm{~mm} \\
\text { From all sides }\end{array}$ \\
\hline & $\begin{array}{r}\text { Basic density } \\
500 \text { to } 700 \mathrm{~kg} / \mathrm{m}^{3}\end{array}$ & $\begin{array}{l}12.03 \mathrm{~kg} / \mathrm{m}^{3} \\
(4.22 \mathrm{~kg} \text { of active elements) }\end{array}$ & $\begin{array}{l}\text { Irregular, } 1 \text { to } 2 \mathrm{~mm} \text { penetration } \\
\text { From all sides }\end{array}$ \\
\hline
\end{tabular}

Note: No low density wood shingles were treated.

Retention value for the roof shingles was unneccessarily high. The described treatment is subject to further experimental work with concentration of solution reduced to approximately $3 \%$ in the hot and cold bath.

The recommencied retention of chemicals (dry salt) is approximately between 10 and $14 \mathrm{k}$ $\mathrm{g} / \mathrm{m}^{3}$ (3.5 to $4.9 \mathrm{~kg}$ of active eiements), e.g.. 2,564 shingles of standard size. The level of retention depends on the service condition, e.g., high humidity in tropical climate adds to the risk of possible biological decay.

Preservation treatment by seaking shingles in ammoniacal copper borate

In general, because of low toxicity of ammonical copper borate, it has potential to be used for roofing and sidewall shingles, especially in places where domestic supply of water is collected from the roof. It is reported to be effective as an insecticide or fungicide.

No data on retention and penetration for Coconut Palm wood are available.

Coconut Palm wood shingles can be treated by less effective methods such as cold dipping or brushing using the following wood preservatives:

1. Cuprinol direct as supplied.

2. Creosote direct as supplied (more suitable for agricultural auxilliary buildings as it has tendency of bleeding especially in hot climate).

3. $6 \%$ tanalith solution.

0

4. Other suitable commercial brand of wood preservatives.

${ }^{1)}$ Recommended density for roofing shingles. 
Note: All these wood preservatives can be applied by brush or by dipping and can be used for regular re-coating in installed roof or sidewall shingles.

\section{Water repellent wood preservatives}

Water repellent wood preservatives can be applied in 2 or 3 years, interval by brush over roof shingles. A number of brands of this type of preservatives are commercially available, or solution can be prepared as follows.

For approximately 15 liters of waterproof preservative:

$1.20 \mathrm{~kg}$ Pentachlorophenol (dry powder) dissolved in 1 liters of paint thinner (10\% concentration, purity of commercial Pantachlorophenol is approximately 85\%)

13/4 liters boiled linseed oil

200 grams Parafin wax (melted in moderate heat)

8 liters diesel fuel oil

4-5 liters turpentine of mineral spirit

Mix together (add liquified Parafin wax to solution before adding boiled linseed oil).

Color pigment can be added when applied to exterior sidewall shingles (approximately 100 grams of color pigment is added for each 4 liters of waterproof preservative).

Note: When standard 5\% Pentachlorophenol is used (in liquid form), use:

$5 \quad$ liters of $5 \%$ Pentachlorophenol

$31 / 4 \quad$ liters boiled linseed oil

200 grams Parafin wax

$5 \quad$ liters diesel fuel oil

add mineral spirit or turpentine to make a total of 15 liters.

When applied by brush on the shingle roof especially in humid and hot olimates, butt and joints should be treated thoroughly.

Waterproof coating can be applied over shingles treated by wood preservative before installation, or untreated installed shingles. Waterproof preservative should be applied immediately after installation and re-coated after 12 months. Re-coating should be done every 2 to 3 years. Spreading rate is approximately 4 liters per 12 to 15 square meters of laid shingles.

Note: Application of waterproof preservative to wood cross section area considerably reduces the absorption of moisture.

All wood preservatives are, more of less, toxic. Waterborne preservatives containing arsenic (CCA types) are highly toxic. The danger of leaching of arsenic to drinking water, especially in regions where domestic water is collected from the roof, is considerably limited if shingle roof is coated regularly by waterproof preservative. 


\section{G. Advantages of Wood Shingles}

1. Excllent insulation properties suitable tor ail climatic conditions.

2. Resistance to high wind damage.

3. Attractive appearance on roof or sidewalls.

4. Life of Coconut Palm wood shingles:

It is difficult, at this stage of Coconut Palm wood shingles application, to forecast the length of life especially as a roofing material. But it can be safely assurned that if roofing shingles arc correctly selected, installed and treated by wood preservative, the serviceabic fife can match that of roof shingles made from a number of commercial wood species.

5. Shingle roof can be over-roofed without necessarily removing the old shingle roof. A number of different roofing materials or new shingles can be laid over.

6. Higher cost of shingle roof can be offset by omitting the construction of ceiling for decorative or insulation reasons.

Internal finish of shingles is quite acceptable. See Fig. 9

Metal roof, without some kind of insulation, radiates excessive heat.

H. Summary of the Most Important Factors

1. For roof and external siding walls, shingles should be selected by density as described. Shingles made from low density wood should be avoided for roofing application. Defective shingles such as splitted, warped, or affected by biological decay should be avoided for any application, especially for prime building roofings.

2. Narrow shingles with less warp, $100 \mathrm{~mm}$ wide and $400 \mathrm{~mm}$ long have been found most suitable for the roofing application.

3. Only dry shingles should be installed.

4. Weather exposure, for the $400 \mathrm{~mm}$-long shingles, should be approximately $1 / 3(125-130$ $\mathrm{mm})$.

5. Spacing between shingles should not be less than 5 or $6 \mathrm{~mm}$. Shingle joints should be overlapped by succeeding shingle course at least $38 \mathrm{~mm}$.

6. Rust resistant nails should be used. The recommended size is G. 12 (2.77 mm diameter), 38 $\mathrm{mm}$ long, if possible ringed (threaded).

7. Shingles should be pre-drilled before driving nails and if the dimension of nails used is as recommended, drill bit should not be larger than $2.1 \mathrm{~mm}$ diameter (5/64").

8. Shingles for roofing installation should be treated by wood preservative before installation and maintained by applying brush coat of waterproof wood preservative in 3 to 4 years intervals. 
9. Shingle roof in tropical countries should have good drying ventilation on the internal side of roof. Therefore, close decking or underlayer of plywood is not recommended without providing waterproof barrier between shingles and decking. 